\title{
An Online Doctorate for Researching Professionals
}

\author{
Emma Abruzzo \\ PhD Student \\ University of Pittsburgh \\ eta9@pitt.edu
}

\author{
Kumar, S., \& Dawson, K. (2018). An Online Doctorate for Researching Professionals. Athabasca \\ University Press. 214 pp. Paperback: \$43.95. ISBN 978-177199-207-7.
}

In their new book An Online Doctorate for Researching Professionals, Kumar and Dawson (2018) detail the lessons they learned from implementing and executing an online EdD program at University of Florida. This book is a compilation of all that they have learned, with the aim of helping program leaders and higher education professors at other institutions to develop or improve their own online EdD programs for working professionals. I recommend this book for any faculty member or institution possessing the goal of developing or improving an online EdD program.

Kumar and Dawson (2018) present their model for online professional doctorate programs and offer guidance for other program leaders of online EdD programs. Their stated goals in implementing the online Ed.D. program at University of Florida were:

...to create an online doctoral program that would enable candidates to build an online community of inquiry, to engage in critical discourse within a specific discipline and/or in an interdisciplinary setting, to learn from and with experts and peers, and to generate knowledge based on existing and original research. (p. 5)

Building on seminal works such as The Theory and Practice of Online Learning (Anderson, 2008), Handbook of Distance Education (Moore, 2013), Online Distance Education: Toward a Research Agenda (Zawacki-Richter \& Anderson, 2014), and Distance Education: A System View of Online Learning (Moore \& Kearsley, 2012), Kumar and Dawson (2018) share their insight from research surrounding the implementation of an online EdD, key points of discussion, nuances, and pitfalls of designing online programs.

The book is organized into three parts: Part I: Theoretical Foundations and Design, Part II: Implementation, and Part III: Ensuring and Evaluating Quality. Each part provides an important contribution to the field about the purpose and practicality of implementing an online EdD program. I will examine the contributions and challenges of each part.

In Part I, the focus is on developing the idea that online professional doctorates are important and valuable. The authors provide a background of the history; characteristics; and theory, research, and practice of the EdD. They claim that "it is not only possible but, in our opinion, preferable for a professional doctorate that combines theory, research, and practice to be offered using the online medium" (p. 19). The authors advocate for an online EdD, not as a less prestigious option, but as ideal for certain graduate students.

The authors offer key considerations for those who are considering starting an online EdD program, such as defining a purpose or goal, identifying prospective learners, identifying existing and needed resources, and involving stakeholders. These are valuable for the intended audience, faculty members and institutions, because they provide a starting point for the complicated process of starting a new program. Additionally, they provide learning theories for program theoretical foundations.

EdD students at University of Florida are expected to combine practice with theory so they are encouraged to bring that mindset into their coursework. One of the strongest components of An Online Doctorate for Researching Professionals is its attention to the small details of how the University of Florida's program functions in relation to the larger suggestions for the development of any online EdD program. The authors provide a detailed description of the required coursework and the sequence of courses at their institution, revealing overarching considerations when designing curriculum. This section provides valuable information on what to do in an online EdD program, but only vaguely touches on how they have adapted and overcome obstacles, painting the process in a very rosy light. For example, the authors note that students from certain professional contexts such as private corporations or the military had challenges with the structure of the program requiring sharing with peers. However, they failed to provide information about how these challenges were addressed.

In Part II: Implementation, the authors detail how an online program can foster inquiry communities and scholarly thinking, and how to mentor and guide students throughout the program and in their dissertation phase. There is a focus on community building and the need to provide a safe space for students to engage with each other. Socialization is an important consideration both before the dissertation phase and during. Online programs require a different type of socialization than that of their on-campus counterparts. The goal of the online community is to foster spaces for this meaningful reflection. This part provides faculty members with guiding principles for assisting and mentoring students throughout the dissertation process as well. These guiding principles mirror those of other doctoral programs; however, their implementation in online programs is quite different and merits the detailed descriptions provided in this book.

The authors present desirable guideline for online EdD programs based on some of the challenges and pitfalls the University of Florida has encountered (pp. 130-133). They describe narrow and definitive guidelines for how to implement an online program. The
New articles in this journal are licensed under a Creative Commons Attribution 4.0 United States License.

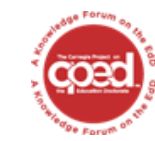

This journal is supported by the Carnegie Project on the Education Doctorate: A Knowledge Forum on the EdD (CPED) cpedinitiative.org 
book sometimes struggles to differentiate from that which applies to all online programs and concrete details of one online program. There are some liberties taken at certain points in assuming, for example, that all programs will follow a cohort model and basing guidelines on that assumption. However, assuming some agency on the part of the reader, the audience is able to pick and choose applicable program components.

Part III: Ensuring and Evaluating Quality focuses on how to maintain quality in online EdD programs as well as how to identify the impact of program content and design. The authors provide a Quality Scorecard tool that can be applied to other institutions and programs. Additionally, they detail lists of methods for assessing programs ranging from faculty interviews to Facebook interaction surveys (pp. 142-143). After defining what impact means in a specific context, it can be measured using both quantitative and qualitative methods. The authors suggest implementing a similar data collection strategy as they employ at University of Florida, which is laid out year-by-year. All of these methods are described in detail with specific examples of implementation provided (pp. 172-176).

The authors suggest that readers can assess their own online EdD programs using the same methods that were used in the development of this book in analyzing the University of Florida's online EdD program. In order to collect the data for their writing, the authors had to evaluate their program. They did so using interviews, surveys, focus groups, and primary source analysis. They were able to analyze the data collected from these multiple methods to then change and adapt their program as well as to highlight the important aspects of an online EdD program. The authors noted, "based on the data we have collected during our research on the UF EdD EdTech... we strongly recommend the use of a cohort model and a consistent focus on community building for a successful online professional doctorate" (p. 71). Therefore, it is through their own data collection and analysis, that they provided suggestions to other institutions for methods to use in assessing online EdD programs.
I highly recommended this book to any person or institution considering implementing an online EdD program or an online component in an on-campus EdD program. I also recommend it to anyone interested in improving their online EdD program or any online higher education program. It is an informative book filled with rich examples directly from the experiences of the authors. This program does, however, focus primarily on the findings from one program within one institution, so it will not provide a wealth of information on different approaches to online EdD programs. Therefore, not all of the information will be universally applicable or equally useful. With that limitation comes an occasional absence of acknowledgment that there may be structural and philosophical differences between this program and others. That being said, Kumar and Dawson (2018) provide broad and rich suggestions and examples in a comprehensive book that all institutions designing or improving an online EdD would, at least in part, find extremely useful.

\section{REFERENCES}

Anderson, T. (Ed.). (2008). The theory and practice of online learning (2nd ed.). Edmonton, AB: Athabasca University Press.

Moore, M. G. (Ed.). (2013). Handbook of distance education (3rd ed.). New York, NY: Routledge.

Moore, M. G., \& Kearsley, G. (2012). Distance education: A systems view of online learning. Belmont, CA: Wadsworth, Cengage Learning.

Zawacki-Richter, O., \& Anderson, T. (Eds.). (2014). Online distance education: Towards a research agenda. Edmonton, AB: Athabasca University. 